\title{
The back and forth transformation between homogeneity and heterogeneity of Cd in marine bay
}

\author{
Dongfang Yang ${ }^{1,2, a}$, Haixia Li ${ }^{1}$, Longlei Zhang ${ }^{1}$, Jiangmin $\mathrm{Li}^{1}$, Nan Nan ${ }^{1}$ \\ ${ }^{1}$ Accountancy Shool, Xijing University, Xian 710123, China; \\ ${ }^{2}$ North China Sea Environmental Monitoring Center, SOA, Qingdao 266033, China. \\ adfyang_dfyang@126.com.
}

Keywords: Cd; Transformation; Mechanism; Homogeneity; Jiaozhou Bay.

\begin{abstract}
Cd pollution in marine bay is one of the critical environmental issues, and therefore understanding the distribution characteristics of $\mathrm{Cd}$ is essential to environmental conservation. It has been found in previous studies that the distribution of pollutants in marine bay has feature of homogeneity, and this paper tried to analyze the mechanism of Cd's homogeneity based on investigation data in Jiaozhou Bay, eastern China. Results showed that the distributions of Cd contents in marine bay could be transformed between homogeneity and heterogeneity. In case of little or small Cd input to the bay, the distribution of $\mathrm{Cr}$ was homogeneity. While in case of large input, the distribution was heterogeneity. In generally, the heterogeneity was determined by Cd input, while the homogeneity was determined by tide and marine current.
\end{abstract}

\section{Introduction}

Many marine bays have been polluted along with the rapid increasing of economic and population [1-2]. Understanding the distribution characteristics of Cd is essential to environmental conservation [3-4]. Cd pollution in marine bays is one of the critical environmental issues since Cd has been widely used in industry and agriculture [5-6]. Jiaozhou Bay is a semi-closed bay in Shandong Province, eastern China. This paper analyzed the mechanism of Cd's homogeneity based on investigation data in Jiaozhou Bay in different seasons in 1979. It was found that the distribution of Cr was homogeneity in case of little or small Cd input to the bay, while in case of large inputthe distribution was heterogeneity. The heterogeneity was determined by $\mathrm{Cd}$ input, while the homogeneity was determined by tide and marine current. These findings provided basis for pollution control and environmental remediation in marine bays.

\section{Study area and data collection}

Jiaozhou Bay is located in the south of Shandong Province, eastern China $\left(35^{\circ} 55^{\prime}-36^{\circ} 18^{\prime} \mathrm{N}\right.$, $120^{\circ} 04^{\prime}-120^{\circ} 23^{\prime} \mathrm{E}$ ), with the total area, average water depth and bay mouth width of $446 \mathrm{~km}^{2}, 7 \mathrm{~m}$ and $3 \mathrm{~km}$, respectively. This bay is a typical of semi-closed bay connected to the Yellow Sea in the south. There are a dozen of rivers including Dagu River, Haibo Rriver, Licun Rriver, and Loushan Rriver etc., all of which are seasonal rivers [3-4]. The investigation on Cd in Jiaozhou Bay was carried on in May, August and November 1979 in eight investigation sites (i.e., H34, H35, H36, H37, H38, H39, H40, H41) (Fig. 1). Pb in waters was sampled and monitored follow by National Specification for Marine Monitoring [7]. 


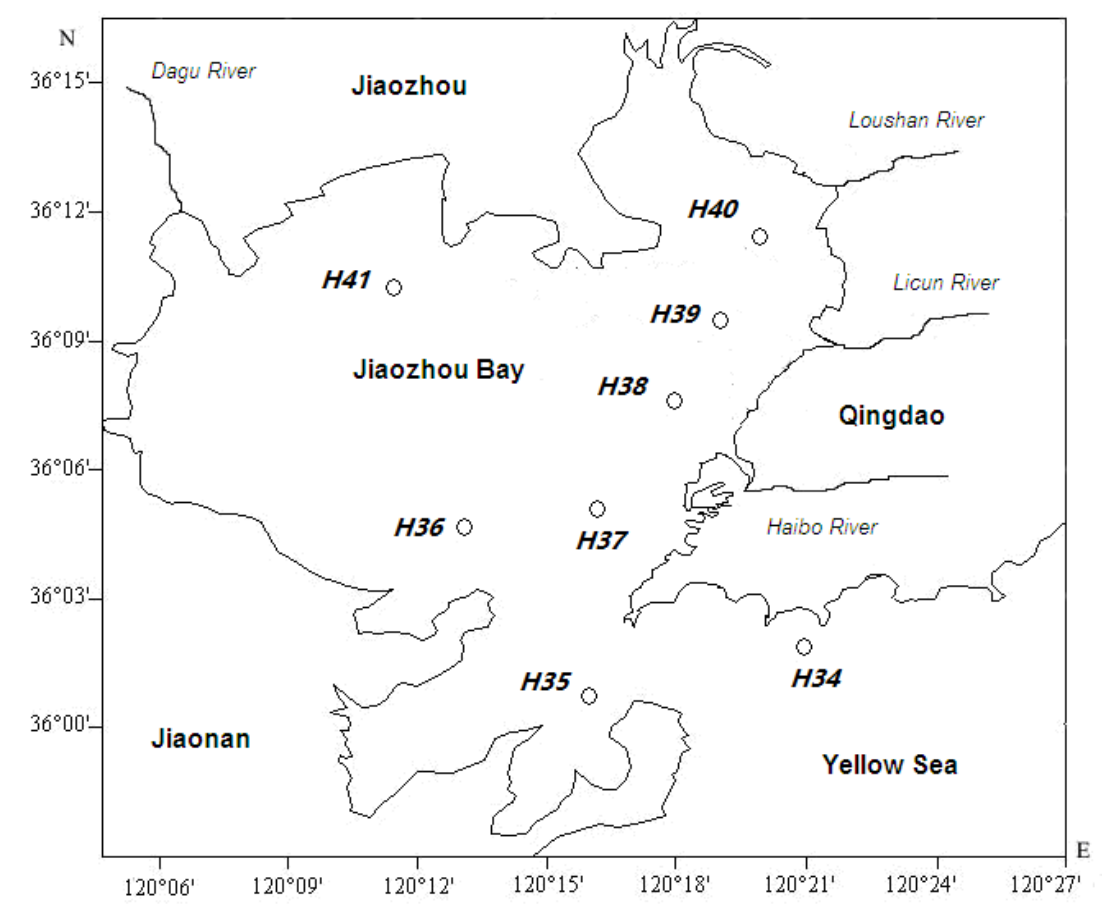

Fig. 1 Geographic location and sampling sites in Jiaozhou Bay

\section{Results}

\subsection{Distributions of Cd.}

In May 1979, the highest Cd content $\left(0.07 \mu \mathrm{g} \mathrm{L}^{-1}\right)$ was in $\mathrm{H} 38$ and $\mathrm{H} 39$ in coastal waters in the estuary of Licun River (Fig. 2a). The high value region was in coastal waters in the northeast of the bay, and Cd contents were forming a series of semi-circles which were decreasing from the north to the south of the bay $\left(0.04 \mu \mathrm{g} \mathrm{L}^{-1}\right)$ (Fig. 2a). In August 1979, the highest Cd content $\left(0.85 \mu \mathrm{g} \mathrm{L}^{-1}\right)$ was in H38 in coastal waters between the estuaries of Licun River and Haibo River (Fig. 2b). The high value region was in coastal waters in the east of the bay, and Cd contents were forming a series of semi-circles which were decreasing from the high value center to waters around $\left(0.01 \mu \mathrm{g} \mathrm{L}^{-1}\right)$ (Fig. 2b). In November 1979, the highest Cd content $\left(0.25 \mu \mathrm{g} \mathrm{L}^{-1}\right)$ was in H34 in open waters outside the bay mouth (Fig. 2c). The high value region was in open waters, and $\mathrm{Cd}$ contents were forming a series of parallel lines which were decreasing from the open waters to the coastal waters in the east of the bay $\left(0.02 \mu \mathrm{g} \mathrm{L}^{-1}\right)$ (Fig. 2c).

\subsection{Inputs of Cd.}

The major Cd source in Jiaozhou Bay is stream flow. In according to the spatial distribution of Cd (Fig. 2), it could be found that the contents of Cd in May, August and November 1979 were 0.04-0.07 $\mu \mathrm{g} \mathrm{L}^{-1}, 0.01-0.85 \mu \mathrm{g} \mathrm{L} \mathrm{L}^{-1}$ and $0.02-0.04 \mu \mathrm{g} \mathrm{L}^{-1}$, respectively, and the source strengths of Cd in May, August and November 1979 were $0.07 \mu \mathrm{g} \mathrm{L}^{-1}, 0.85 \mu \mathrm{g} \mathrm{L}^{-1}$ and $0.00 \mu \mathrm{g} \mathrm{L}^{-1}$, respectively, and the variation ranges of Cd content in May, August and November 1979 were $0.03 \mu \mathrm{g} \mathrm{L}^{-1}, 0.84 \mu \mathrm{g} \mathrm{L}^{-1}$ and $0.02 \mu \mathrm{g} \mathrm{L}^{-1}$, respectively. The input of Cd was small in May, and was high in August, and was little in November. 

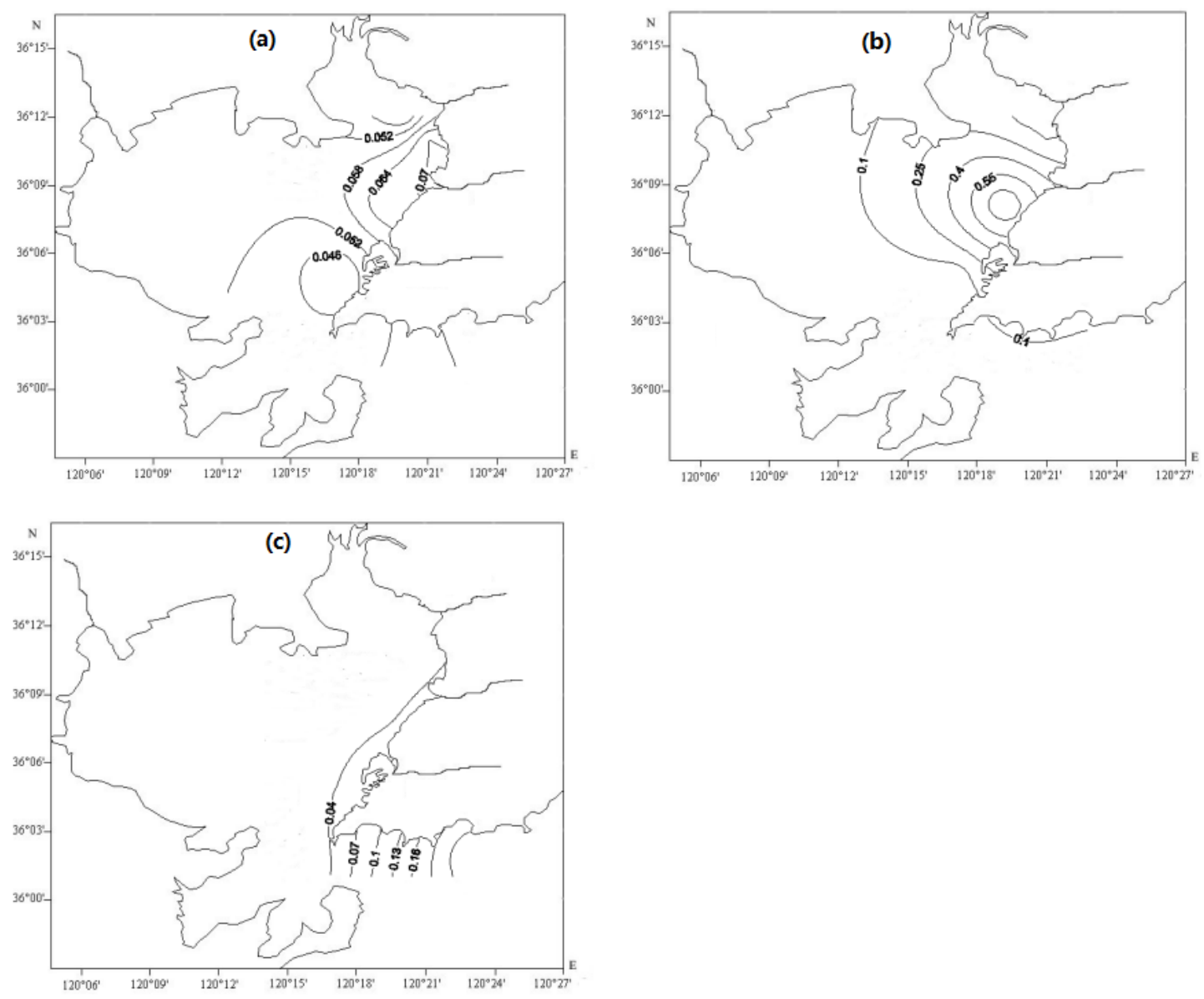

Fig. 2 Horizontal distribution of Cd in Surface waters in Jiaozhou Bay in a) May, b) August and c) November1979/ $\mu \mathrm{g} \mathrm{L}^{-1}$

\section{Discussion}

\subsection{Homogeneity of distributions of substances.}

All of the substances in the ocean are stirring and transporting by marine current and tide, resulting in the well-distributed of their contents [8]. Tide is the major force in coastal waters, while in the open sea marine current is responsible, as well as the the assistant of storm and earthquake [9-11]. Hence, the ocean makes all of the substances being homogeneity well-distributed as time passes by, and the ocean has the feature of homogeneity.

\subsection{Homogeneity and heterogeneity of distributions of $\mathrm{Cd}$.}

Cd contents in May 1979 were $0.04-0.07 \mu \mathrm{g} \mathrm{L}^{-1}$, with a small variation of $0.03 \mu \mathrm{g} \mathrm{L}^{-1}$ (Fig. 2a), indicating feature of homogeneity. The input of Cd from stream flow was very small in May 1979, and there was a relative high value region in estuary of Licun River, while in other locations the Cd contents were very low and well-distributed (0.02-0.04 $\left.\mu \mathrm{g} \mathrm{L}^{-1}\right)$. Cd contents in August 1979 were 0.01-0.85 $\mu \mathrm{g} \mathrm{L}^{-1}$, with a big variation of $0.84 \mu \mathrm{g} \mathrm{L}{ }^{-1}$, indicating that distribution of Cd (Fig. 2b) had feature of heterogeneity. The input of Cd from stream flow was very high in August 1979, and the distributions of Cd were nonuniform distributed in generally. Cd contents in November 1979 were 0.02-0.04 $\mu \mathrm{g} \mathrm{L}^{-1}$, with a very variation of $0.02 \mu \mathrm{g} \mathrm{L}{ }^{-1}$, indicating that distribution of Cd (Fig.2c) had feature of homogeneity. The input of Cd from stream flow was little in November 1979, and the distributions of Cd were well-distributed in generally.

\subsection{Transformation mechanism of homogeneity and heterogeneity of distributions of $\mathrm{Cd}$.}

In generally, the high value of $\mathrm{Cd}$ in Jiaozhou Bay was mainly determined by the inputs of 
stream flow. In according to the spatial-temporal distributions of Cd in different seasons, it could be found that Cd's horizontal distribution in marine bay could be transformed between homogeneity and heterogeneity. In case of little or small Cd input to the bay (May 1979 of November 1979), the distribution of Cr was homogeneity. While in case of large input, the distribution was heterogeneity (August 1979). In generally, the heterogeneity was determined by Cd input, while the homogeneity was determined by tide and marine current.

\section{Conclusions}

By means of the analysis of the horizontal distributions of Cd contents in different seasons in Jiaozhou Bay, it was found that the distributions of had features of both homogeneity and heterogeneity that could be transformed. The transformation mechanism was further revealed. The distribution of $\mathrm{Cr}$ was homogeneity in case of little or small $\mathrm{Cd}$ input to the bay, yet was heterogeneity in case of large input. The heterogeneity was determined by $\mathrm{Cd}$ input, while the homogeneity was determined by tide and marine current.

\section{Acknowledgment}

This research was sponsored by the China National Natural Science Foundation (31560107), Doctoral Degree Construction Library of Guizhou Nationalities University, Education Ministry's New Century Excellent Talents Supporting Plan (NCET-12-0659), tMajor Project of Science and Technology of Guizhou Provincial ([2004]6007-01), Guizhou R\&D Program for Social Development ([2014] 3036) and Research Projects of Guizhou Nationalities University ([2014]02), Research Projects of Guizhou Province Ministry of Education (KY [2014] 266), Research Projects of Guizhou Province Ministry of Science and Technology (LH [2014] 7376).

\section{References}

[1] Yang DF, Chen Y, Wang H, et al.: Coastal Engineering, Vol. 29 (2010), p. 73-82.

[2] Yang DF, Chen Y, Liu CX, et al.: Coastal Engineering, Vol. 32(2013), p. 68-78.

[3] Yang DF, Chen Y, Gao ZH, et al.: Chinese Journal of Oceanology and Limnology, Vol. 23(2005), p. 72-90. (in Chinese)

[4] Yang DF, Wang FY, Gao ZH, et al. Marine Science, Vol. 28 (2004), p. 71-74. (in Chinese)

[5] Yang DF, Ding ZR, Zheng L, et al.:Coastal Engineering, Vol. 30(2011), p. 66-74.

[6] Yang DF, Wang FY, Zhu SX, et al.: Proceedings of the 2015 international symposium on computers and informatics, Vol. (2015), p. 2661-2666.

[7] China's State Oceanic Administration: The specification for marine monitoring (Ocean Press, Beijiang 1991), p.1-300. (in Chinese)

[8] Yang DF, Zhu SX, Wu YJ, et al.: Advances in Engineering Research, Vol. 31 (2015), p. 1288-1291.

[9] Yang DF, Zhu SX, Wang FY, et al.: Advances in Engineering Research, Vol. (2015), p. 427-430.

[10] Yang DF, Yang DF, Zhu SX, et al.: The spreading process of Pb in Jiaozhou Bay [J]. Advances in Engineering Research, Vol. (2016), Part G, p. 1921-1926.

[11]Yang DF, Wang FY, Zhu SX, et al.:Advances in Engineering Research, Vol. 65 (2016), p. 298-302. 